\title{
Esophageal stricture associated with epidermolysis bullosa
}

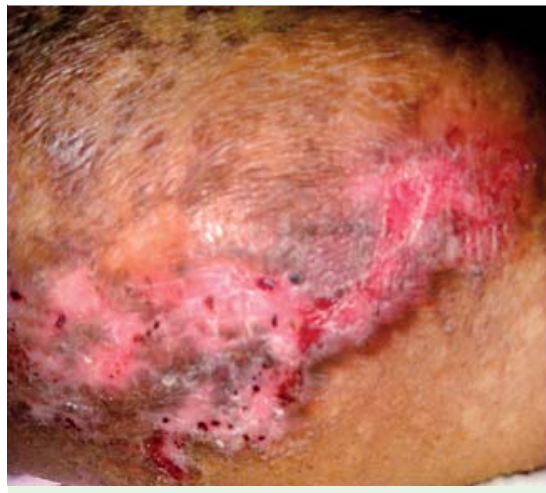

Fig. 1 An erythematous maculopapular lesion in a young woman with epidermolysis bullosa, presenting with dysphagia and odynophagia.

A 20-year-old woman diagnosed as having epidermolysis bullosa acquisita (EBA) presented with dysphagia and odynophagia. Upper gastrointestinal endoscopy revealed a web in the upper esophagus, for which endoscopic dilatation was done. Following this, the patient remained asymptomatic for 2 years, after which she again presented with recurrence of symptoms. Clinical examination showed multiple erythematous and maculopapular skin eruptions, predominantly on the face and nape of the neck ( $\bullet$ Fig. 1). Laboratory investigation revealed increased total white cell count, hemoglobin $10 \mathrm{~g} / \mathrm{dL}$, and a raised erythrocyte sedimentation rate (ESR). Despite the patient being on treatment with steroids for her primary disease, she had an acute exacerbation with severe dysphagia and odynophagia. A barium swallow showed a tight stricture in a small segment of the upper esophagus $(\bullet$ Fig.2). Upper gastrointestinal endoscopy ( Fig.3) also showed the tight stricture in the upper esophagus, with friable, edematous mucosa. The endoscope could not be passed beyond the stricture, and the patient underwent careful endoscopic balloon dilation ( Fig.4) under general anesthesia. She recovered well postoperatively and was gradually started on feeds, which she was able to swallow comfortably.

Epidermolysis bullosa involves not only the skin but also the internal organs that are lined with squamous epithelium.

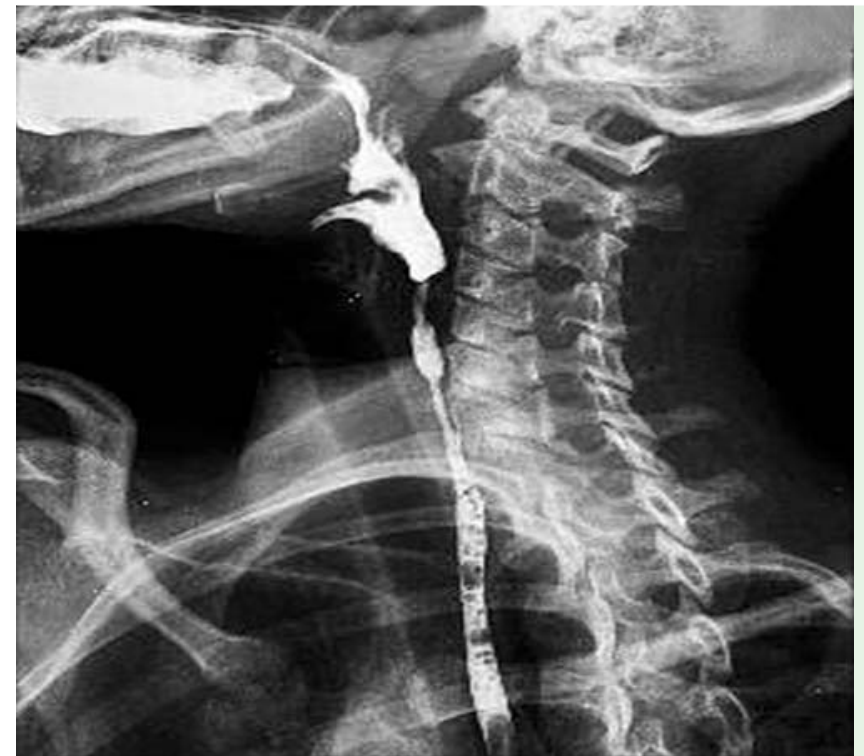

Fig. 2 Barium swallow showing a tight stricture in the upper esophagus.

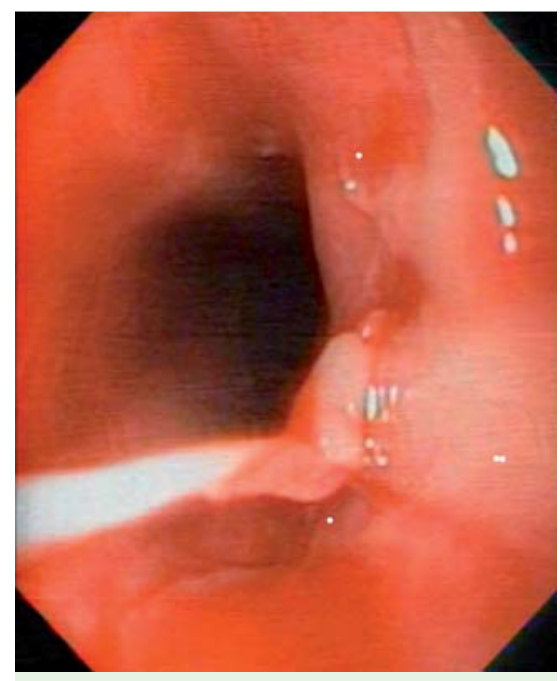

Fig. 3 Endoscopy showing mucosal edema, ulceration, and narrowing in upper esophagus.

Clinically, the disease presents in three main forms, with mild inflammatory form of EBA being the commonest. Mucosal involvement can lead to complications such as esophageal strictures causing dysphagia [1-3]. Intensive nutritional support followed by balloon dilation is the first choice of treatment for esophageal strictures complicating epidermolysis bullosa. By following this regimen, invasive surgery can be avoided [4]. There is no satisfactory medical treatment of dys-

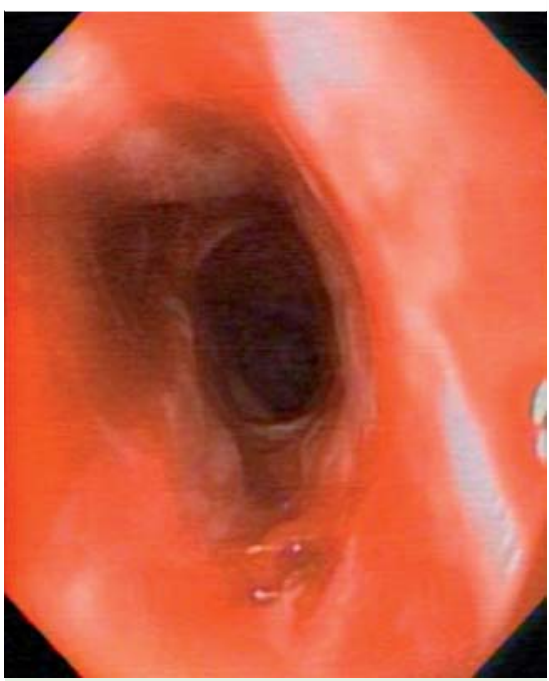

Fig.4 Endoscopic appearance following esophageal balloon dilation.

phagia, and endoscopic balloon dilation has been found to be a safe and effective approach [5]. However, caution has to be exercised during this procedure due to the likelihood of complications such as bullae formation, bleeding, and perforation at the dilation site.

Endoscopy_UCTN_Code_CCL_1AB_2AC_3AD

\section{Competing interests: None}




\section{R. A. Kothari, S. Shetty, K. Janarthanan}

Department of Medical Gastroenterology, PSG IMSR, Coimbatore, Tamil Nadu, India

\section{References}

1 Tu J, Kumarasinghe PW. Epidermolysis bullosa acquisita with moderately severe dysphagia due to esophageal strictures. Indian J Dermatol 2011; 56 (Suppl. 02): 224 - 227

2 Hallel-Halevy D, Nadelman C, Chen $M$ et al. Epidermolysis bullosa acquisita: Update and review. Clin Dermatol 2001; 19: $712-$ 718
3 Luke MC, Darling TN, Hsu R et al. Mucosal morbidity in patients with epidermolysis bullosa acquisita. Arch Dermatol 1999; 135: 954-959

4 Fujimoto T, Lane GJ, Miyano T et al. Esophageal strictures in children with recessive dystrophic epidermolysis bullosa: experience of balloon dilatation in nine cases. J Pediatr Gastroenterol Nutr 1998; 27 (Suppl. 05): $524-529$

5 Karakan T, Dogan I, Cindoruk M et al. Fluoroscopically guided endoluminal balloon dilation of oesophageal stricture due to dystrophic epidermolysis bullosa in two sisters. Acta Gastroenterol Belg 2006; 69 (Suppl. 03): $327-329$
Bibliography

Dol http://dx.doi.org/

10.1055/s-0032-1309917

Endoscopy 2013; 45: E241-E242

(c) Georg Thieme Verlag KG

Stuttgart · New York

ISSN 0013-726X

\section{Corresponding author}

\section{Dr R. A. Kothari}

PSG Institute of Medical Sciences and Research Peelamedu

Coimbatore 641004

Tamil Nadu

India

Fax: $+422-2594401$

dr.rahulkothari11@gmail.com 